Xinhua Zhan, MD

Boryana Stamova, PhD

Lee-Way Jin, MD

Charles DeCarli, MD

Brett Phinney, PhD

Frank R. Sharp, MD

Correspondence to

Dr. Zhan:

xzhan@ucdavis.edu
Supplemental data at Neurology.org

\title{
Gram-negative bacterial molecules associate with Alzheimer disease pathology OPEN
}

\section{ABSTRACT}

Objective: We determined whether Gram-negative bacterial molecules are associated with Alzheimer disease (AD) neuropathology given that previous studies demonstrate Gramnegative Escherichia coli bacteria can form extracellular amyloid and Gram-negative bacteria have been reported as the predominant bacteria found in normal human brains.

Methods: Brain samples from gray and white matter were studied from patients with AD $(n=24)$ and age-matched controls ( $n=18$ ). Lipopolysaccharide (LPS) and E coli K99 pili protein were evaluated by Western blots and immunocytochemistry. Human brain samples were assessed for $E$ coli DNA followed by DNA sequencing.

Results: LPS and E coli K99 were detected immunocytochemically in brain parenchyma and vessels in all $A D$ and control brains. K99 levels measured using Western blots were greater in AD compared to control brains $(p<0.01)$ and $K 99$ was localized to neuron-like cells in AD but not control brains. LPS levels were also greater in AD compared to control brain. LPS colocalized with $A \beta_{1-40 / 42}$ in amyloid plaques and with $A \beta_{1-40 / 42}$ around vessels in $A D$ brains. DNA sequencing confirmed $E$ coli DNA in human control and AD brains.

Conclusions: E coli K99 and LPS levels were greater in AD compared to control brains. LPS colocalized with $A \beta_{1-40 / 42}$ in amyloid plaques and around vessels in AD brain. The data show that Gram-negative bacterial molecules are associated with AD neuropathology. They are consistent with our LPS-ischemia-hypoxia rat model that produces myelin aggregates that colocalize with $A \beta$ and resemble amyloid-like plaques. Neurology ${ }^{\circledR}$ 2016;87:2324-2332

\section{GLOSSARY}

AD = Alzheimer disease; CERAD = Consortium to Establish a Registry for Alzheimer's Disease; DAPI = 4',6-diamidino-2phenylindole; $\mathbf{G M}$ = gray matter; IL = interleukin; LPS = lipopolysaccharide; NSAID = nonsteroidal anti-inflammatory drug; $\mathbf{W M}=$ white matter.

Although age is the primary risk factor for the late-onset sporadic form of Alzheimer disease (AD), infection has also been implicated. ${ }^{1}$ Infection increases the odds of developing AD by 2-fold over 5 years. $^{2}$ Diphtheria, tetanus, and pertussis; polio; tetanus; and influenza vaccines reduce the risk of subsequent AD. ${ }^{3,4}$ Inflammatory molecules including C-reactive protein and inerleukin-6 are elevated in blood years before dementia., ${ }^{5,6}$ Though clinical trials show that nonsteroidal anti-inflammatory drugs (NSAIDs) do not affect cognitive decline in $\mathrm{AD},{ }^{7}$ some studies suggest that NSAIDs decrease the risk of developing AD. ${ }^{8}$ Indeed, recent studies have demonstrated that sporadic late-onset $\mathrm{AD}$ is associated with infections. ${ }^{9-12}$ However, a consistent link between these agents and AD neuropathology has not been demonstrated.

Gram-negative bacteria like Escherichia coli can deposit amyloid. ${ }^{13,14}$ Moreover, we showed that administration of Gram-negative bacteria-derived lipopolysaccharide (LPS) followed by ischemia-hypoxia produce plaque-like aggregates of $\beta$-amyloid in rat brains. ${ }^{15}$ Though Gramnegative bacteria have been reported as the predominant bacteria found in normal human

From the Department of Neurology (X.Z., B.S., C.D., F.R.S.), MIND Institute (X.Z., B.S., F.R.S.), Alzheimer's Disease Center (L.-W.J., C.D.), Department of Pathology (L.-W.J.), and Proteomics Core Facility, Genome Center (B.P.), University of California at Davis, Sacramento.

Go to Neurology.org for full disclosures. Funding information and disclosures deemed relevant by the authors, if any, are provided at the end of the article. The Article Processing Charge was paid by the authors.

This is an open access article distributed under the terms of the Creative Commons Attribution-NonCommercial-NoDerivatives License 4.0 (CC BY-NC-ND), which permits downloading and sharing the work provided it is properly cited. The work cannot be changed in any way or used commercially. 
brains, ${ }^{16}$ the study did not describe pathologic correlates. Because of our finding that LPS promoted formation of amyloid-like plaques in rat brain, ${ }^{15}$ we determined whether Gramnegative bacterial molecules were associated with human $\mathrm{AD}$ neuropathology.

METHODS Standard protocol approvals, registrations, and patient consents. The institutional review board approved this study. Informed consent was obtained from all participants who were enrolled in studies at the University of California at Davis Alzheimer's Disease Center.

Brain samples. $\mathrm{AD}$ was rated using Consortium to Establish a Registry for Alzheimer's Disease (CERAD) criteria and Braak stage on $24 \mathrm{AD}$ and 18 age-matched controls. Brain tissue was provided by the Alzheimer's Disease Center at the University of California Davis. Superior temporal gyrus gray matter (GM) was studied since it is commonly involved in $\mathrm{AD}$ and frontal lobe white matter (WM) was studied because it shows abnormalities in $\mathrm{AD}$ brains. ${ }^{17}$ Controls were age-matched individuals without cognitive deficits. Formalin-fixed brains used for immunostaining included $11 \mathrm{AD}$ and 7 age-matched controls. Frozen brains used for Western blot analysis and PCR for E coli DNA included $13 \mathrm{AD}$ and 11 agematched controls.

Frozen tissue $\left(\sim 1 \mathrm{~cm}^{3}\right)$ from the superior temporal gyrus GM or frontal lobe WM was removed with sterile technique and frozen at $-70^{\circ} \mathrm{C}$. The tissue surface was treated with $75 \%$ ethanol and removed with a sterile scalpel blade. Frozen tissue was cored with autoclaved trephines and placed in sterile, endotoxinfree tubes at $-70^{\circ} \mathrm{C}$. Formalin-fixed (4\%) brains were blocked, embedded in paraffin, and sectioned for immunostaining.

Immunofluorescence. Detailed methods are described in our previous studies..$^{15,17,18}$ Briefly, after removing paraffin with xylene and rehydrating through graded alcohols, sections were treated with antigen retrieval buffer and autofluorescence eliminator reagent (Millipore, Etobicoke, Canada). Primary antibodies were used in 1:200 concentrations unless stated otherwise. Secondary antibodies included either goat anti-mouse or goat antirabbit Alexa Fluor 488 or 594 (Invitrogen, Carlsbad, CA). Slide mounting medium included 4',6-diamidino-2-phenylindole (DAPI) to stain nuclei (Vector Laboratories, Burlingame, CA). For controls, primary antibody was deleted or immunodepleted with the target antigen of the antibody.

Western blot analysis. Tissue was homogenized in cold RIPA buffer containing a protease inhibitor mixture. After centrifuging homogenates for 30 minutes at $4{ }^{\circ} \mathrm{C}(14,000 \mathrm{~g})$, the pellet was discarded and proteins in the supernatant separated on $10 \%$ sodium dodecyl sulfate polyacrylamide gels. They were then transferred to nitrocellulose membranes and hybridized overnight at $4{ }^{\circ} \mathrm{C}$ with primary antibodies listed below. Antibodies were stained using horseradish peroxidase conjugated anti-rabbit or anti-mouse immunoglobulin G (Bio-Rad, Hercules, CA) combined with electrochemiluminescence detection (Piers). $\beta$-actin staining served as the control. We used NIH Image J software to quantify band intensities.

Primary antibodies were obtained from Abbiotec (San Diego, CA) (glial fibrillary acid protein, 250661; MAG, 250744), Abcam (Cambridge, UK) (E coli LPS, ab35654), Lifespan (Providence, RI) ( $E$ coli K99, LS-C83195), Millipore $\left(A \beta_{1-40 / 42}\right.$, AB5076; NeuN, ABN2300A4; NG2, AB5320), RayBiotech (Norcross, GA) (E coli LPS, MD-05-0148), Santa Cruz
Biotechnology (Dallas, TX) ( $\beta$-actin, sc-69879), ThermoFisher (Waltham, MA) (GST $\pi$, PA529601; Synapsin 2, OSS00020W), and Wako Chemicals (Cape Charles, VA) (Iba1, 019-19741).

PCR for DNA and DNA sequencing. E coli DNA was detected using PCR amplification of an $E$ coli glutamate decarboxylase B $(\operatorname{gadB})$ DNA fragment. ${ }^{19}$ This DNA fragment was selected because it detects all $E$ coli strains, and does not detect the human gene. ${ }^{19}$ All reagents used for PCR were first tested for E coli DNA contamination, which was indicated by detection of $E$ coli DNA in endotoxin free water. Only those reagents that were free of $E$ coli DNA were used for PCR amplification in human brains. Brain genomic DNA samples were isolated and purified using PureLink Genomic DNA Kits (K1820-01, Life Technologies, Carlsbad, CA). Approximately $20 \mathrm{mg}$ of minced brain tissue from superior temporal gyrus was digested and DNA was eluted and frozen. E coli DNA from the ATCC 8739 strain (ATCC) was used as a positive control. PCR amplification was performed in a $50 \mu \mathrm{L}$ reaction mixture, containing $10 \mathrm{ng}$ of DNA, $25 \mu \mathrm{L}$ of $2 \times$ GoTaq Colorless Master Mix (Promega, Madison, WI), and $0.5 \mu \mathrm{M}$ primer mix. The reaction mixtures were placed in a Gene Amp PCR System 9700 (Applied Biosystems, Foster City, CA) with the following settings: 5 minutes at $94^{\circ} \mathrm{C}$, followed by 38 cycles of 40 seconds at $94^{\circ} \mathrm{C}, 45$ seconds at $57^{\circ} \mathrm{C}, 30$ seconds at $72^{\circ} \mathrm{C}$, and a final extension time of 7 minutes at $72^{\circ} \mathrm{C}$. Amplified products were analyzed in an Agilent (Santa Clara, CA) 2100 Bioanalyzer. Identification of the $\mathrm{gadB}$ gene was confirmed by a $3^{\prime}$ and $5^{\prime}$ Sanger DNA sequencing assay on 3 control and $3 \mathrm{AD}$ samples at the UC Davis DNA Sequencing Facility. PCR products were sequenced with BigDye Terminator v 3.1 Cycle Sequencing Kit with Gel Company Better Buffer and postcycle sequencing purification was achieved at a Beckman Coulter (Sharon Hill, PA) Biomek NXp laboratory automation workstation with Beckman-Coulter CleanSEQ magnetic bead purification. Data were analyzed with ABI Prism (Applied Biosystems) 3730 genetic analyzer, ABI Prism 3730 data collection software v 3.0, and ABI Prism DNA sequencing analysis software v 5.2. DNA primers used in this study for PCR amplification and DNA sequencing were forward sequence $\left(5^{\prime} \rightarrow 3^{\prime}\right) \quad$ CACGTTTTGGTGCGAAGTCT and reverse sequence $\left(5^{\prime} \rightarrow 3^{\prime}\right)$ TTGTGGACATTTTCGTCGTC (Eurofins MWG, Huntsville, AL). Amplicons were 175 bp with amplicon accession number M84025.1. ${ }^{19}$

Statistical analysis. Differences between groups were analyzed using a Student $t$ test (continuous), Wilcoxon-Mann-Whitney test (ordinal), or Fisher exact test (categorical). Differences between multiple groups were analyzed using one-way analysis of variance with Student-Newman-Keuls post hoc test. A $p<0.05$ was considered significant.

RESULTS Patient characteristics. There were no significant differences in age or sex between patients with $\mathrm{AD}$ and controls (table e-1 at Neurology.org). The differences in median Braak and Braak stage ${ }^{20}$ and CERAD plaque scores between $\mathrm{AD}$ and control brains were significant (table e-1).

Detection of $\boldsymbol{E}$ coli $\mathrm{K} 99$ and Gram-negative bacterial LPS in $\mathrm{AD}$ and control brains. Control samples $(\mathrm{n}=10)$ and $\mathrm{AD}$ samples $(\mathrm{n}=13)$ including GM (figure $1 \mathrm{~A}$ ) and WM (figure 1B) were assessed for E coli K99 pili protein. ${ }^{21}$ K99 was present in 9/13 AD GM compared to $1 / 10$ control GM samples $(p=0.006)$ 
Figure 1 Western blot analysis of Escherichia coli K99 pili protein and Gram-negative bacterial lipopolysaccharide (LPS) in human brains
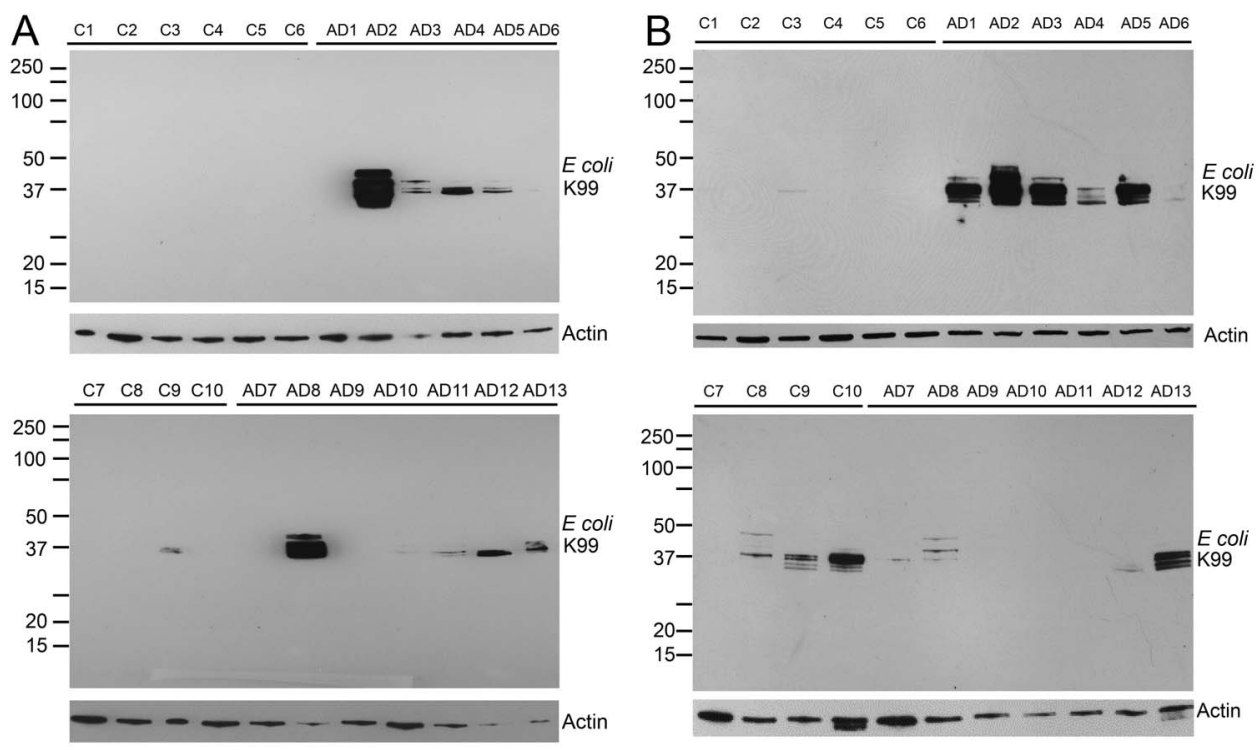

C. E coli $\mathrm{K} 99$ accumulation in aging brains
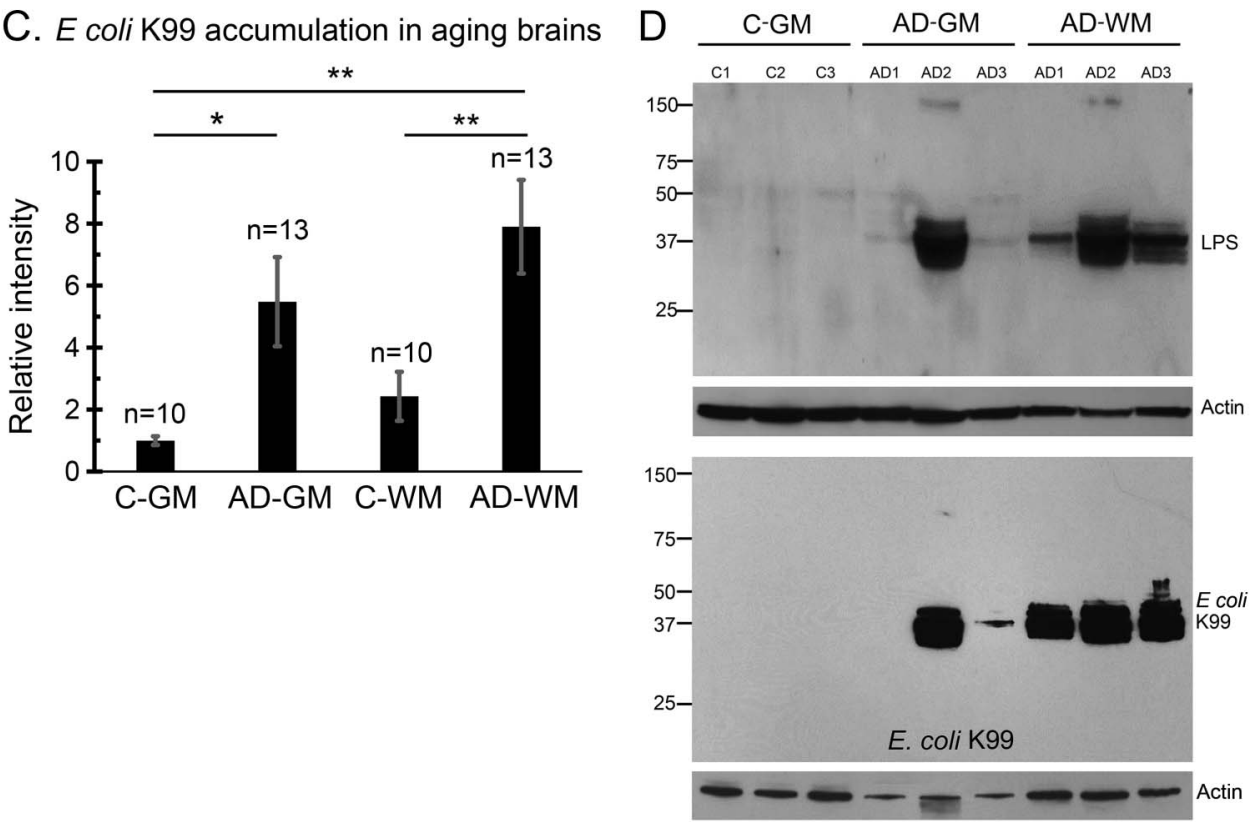

(A) Western blot analysis of E coli K99 pili protein in gray matter (GM). E coli K99 was detected in 9 out of 13 Alzheimer disease (AD) cases and 1 out of 10 control (C) cases. (B) Western blot analysis of $E$ coli K99 pili protein in white matter (WM). $E$ coli K99 was detected in 10 out of 13 AD cases and 4 out of 10 control cases. (C) Quantification of E coli K99 protein. E coli K99 protein levels in AD brains were greater than in control aged brains in both GM $(* p<0.05)$ and WM (**p $<0.01)$. (D) Western blot analysis of Gram-negative bacterial LPS. A total of $3 / 3$ AD GM, 3/3 AD WM, and 0/3 control GM showed LPS. Error bars are standard errors of the mean. $\beta$-actin was used as a loading control.

and in $10 / 13 \mathrm{AD}$ WM compared to $4 / 10$ control WM samples $(p=0.09)$. Quantification showed significantly greater amounts of $E$ coli $\mathrm{K} 99$ protein in AD GM compared to controls and significantly more K99 in AD WM compared to controls (figure 1C).

In addition, we used Western blots to test the specificity of Gram-negative LPS antibody, which was used for the immunocytochemistry studies described below. The LPS Western blots using the Abcam antibody (figure 1D, upper panel) showed a similar pattern of expression as that seen for the K99 Western blots (figure 1D, lower panel). LPS (Abcam antibody) was detected by Western blots in 3/3 AD GM, 3/3 AD WM, and 0/3 control GM (figure 1D). As a control, we repeated the Western blots of $\mathrm{AD}$ brain using another antibody to LPS (RayBiotech) as well as doing a blot after immunoprecipitating the antibody with LPS. The RayBiotech anti-LPS antibody detected a large band at $37 \mathrm{kD}$ and a smaller band at $150 \mathrm{kD}$ (figure e-1), whereas the LPS 
immunodepleted antibody showed the $150 \mathrm{kD}$ band only with complete loss of the $37 \mathrm{kD}$ band (figure e1). This is strong evidence the antibody detects LPS in the $37 \mathrm{kD}$ band, and this is the same molecular weight as the $37 \mathrm{kD}$ large band seen in figure $1 \mathrm{D}$ with the Abcam anti-LPS antibody (upper panel).

Localization of LPS and $\mathrm{K99}$ pili protein in cells in AD and control brains. E coli LPS (Abcam antibody) and K99 pili protein were detected immunocytochemically in all $11 \mathrm{AD}$ and 7 control brains. LPS was detected in control (figure 2, A and C) and AD brains (figure 2, B and D) in GM (figure 2, A and B) and in periventricular WM (figure 2, C and D). For a control, coimmunoprecipitation of the anti-LPS antibody with LPS completely eliminated all tissue staining by immunofluorescence (figure e-2) or by immunohistochemistry (figure e-3), showing that LPS was being immunostained.

LPS was localized in neurons (figures e- 4 and e-5), microglia (figure e-6), oligodendrocytes, and oligodendrocyte progenitor cells (figures e-7 and e-8). LPS colocalized with a nuclear marker, DAPI, in control GM (figure 2E) and WM (figure $2 \mathrm{G}$ ) including ependymal cells (figure 2G, arrowheads). In AD GM there was LPS staining in what appeared to be amyloid plaques in cortex (figure 2, B and F, white arrow). Smaller LPS-stained structures appeared to be nuclei in GM (figure 2, B and F, yellow arrowheads) and WM (figure 2, D and H). Note that ependymal cells were missing in AD brain (figure $2 \mathrm{H}$, arrowheads) and DAPI was absent in many nuclei that were stained with LPS in WM (figure $2 \mathrm{H}$ ).

K99 pili protein was associated with neuron-like cells in $\mathrm{AD}$ cortex (figure $3 \mathrm{~B}$ ) but not in controls (figure 3A). K99 pili protein was localized to control ependymal cells (figure 3C) that were lost in $\mathrm{AD}$ brains (figure 3D, arrowheads). K99 pili protein immunostaining of fiber tracts in AD WM (figure 3D) was greater than in controls (figure $3 \mathrm{C}$ ).

Association of LPS with amyloid plaques in AD brains. LPS positively stained clusters were frequently observed in AD brains (figure e-9, A1, arrow). Within these clusters, DNA stained with DAPI from coalesced cells and was indistinct (figure e-9, A2 and A3, arrows). Moreover, the coalesced DNA colocalized with $A \beta_{1-40 / 42}$ (figure e-9, B1-3, arrows).

LPS and $A \beta_{1-40 / 42}$ colocalized in 3 different patterns in $\mathrm{AD}$ brains. (1) Clusters composed mainly of LPS particles colocalized with $A \beta_{1-40 / 42}$ (figure $4 \mathrm{~A}$ ). (2) $A \beta_{1-40 / 42}$ deposits that colocalized with LPS were surrounded by LPS (figure 4, B and C). (3) The most common pattern showed confluent $A \beta_{1-40 / 42}$ stained amyloid plaques with scattered LPS particles in them (figure 4D).
LPS-stained plaques were surrounded by astrocytes (figure e-10, B1-4, arrows). In AD cortex, LPS was localized in neurons, microglia, oligodendrocytes, and oligodendrocyte progenitor cells (B1-B4, figures e-4 through e-8).

In contrast, K99 pili protein surrounded small $\mathrm{A} \beta_{1-40 / 42}$ stained amyloid plaques (figure 4, E-G), but was absent around larger amyloid plaques (diameter $>50 \mu \mathrm{m}$ ) (figure $4 \mathrm{H}$ ).

Association of LPS and K99 pili protein with blood vessels. In control brains, both LPS (figure 5A) and $E$ coli $\mathrm{K} 99$ (figure 5C) localized to blood vessels that did not stain for $A \beta_{1-40 / 42}$ (figure 5, $A$ and $C$ ). In contrast, LPS and $A \beta_{1-40 / 42}$ colocalized in vessel walls of $\mathrm{AD}$ brains (yellow staining, figure $5 \mathrm{~B}$ ). $\mathrm{A} \beta_{1-40 / 42}$ was sandwiched by but did not colocalize with K99 pili protein in vessels in $\mathrm{AD}$ brains (figure $5 \mathrm{D}$, arrowheads).

E coli $\mathrm{DNA}$ in $\mathrm{AD}$ and control brains. $\mathrm{PCR}$ with primers for the $E$ coli glutamate decarboxylase B gene $(\operatorname{gadB})^{19}$ showed the predicted 175 bp DNA fragment, which was the same size in control and AD GM, as well as in the positive control ATCC $8739 E$ coli strain (figure e-11). The $175 \mathrm{bp}$ amplicon was detected in 9/10 normal control (figure e-11A) and 9/13 AD brains (figure e-11B). Of these, $1 / 10$ control and 4/13 AD samples showed bands of different sizes (figure e-11) of unknown significance. All samples showed low molecular weight bands that likely represented primer interactions. A megablast (optimized for highly similar sequences; NCBI nonredundant nucleotide database) of the DNA sequences (table e-2) of the amplicons from the qPCR reactions showed that DNA from the 3 human controls (table e-2) was $100 \%$ identical to 115 E coli strains/ substrains/entries in the database, and to 5 Shigella strains. The DNA sequence from one of the $\mathrm{AD}$ samples (table e-2) was $100 \%$ identical to 7 strains/ substrains/entries of $E$ coli, while the DNA from the other AD sample (table e-2) had one nucleotide mismatch from $116 \mathrm{E}$ coli strains/substrains/entries, and one mismatch (99.4\% identity) from the same 5 Shigella strains as the other $\mathrm{AD}$ sample. One $\mathrm{AD}$ sample (AD1), negative on quantitative PCR, was also negative upon sequencing.

DISCUSSION We demonstrate Gram-negative bacterial LPS, E coli K99 pili protein, and DNA in control and AD brains. K99 and LPS levels were greater in $\mathrm{AD}$ compared to control brains. Moreover, LPS colocalized with $A \beta_{1-40 / 42}$ in amyloid plaques and with $A \beta_{1-40 / 42}$ around blood vessels in AD brains. These data suggest that Gramnegative bacterial molecules are associated with $\mathrm{AD}$ pathology. 

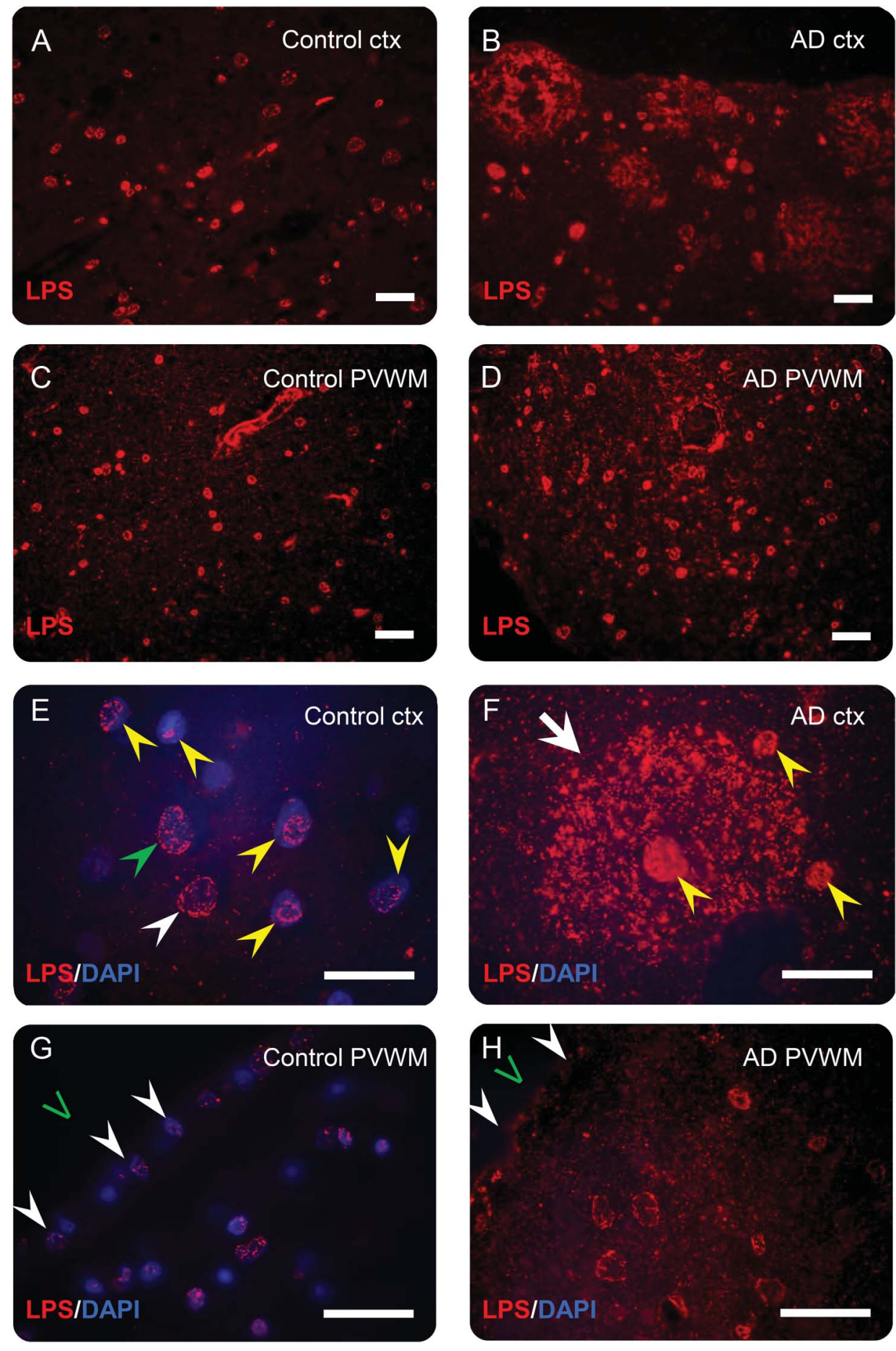

Immunocytochemistry for LPS showed staining in both control $(A, C)$ and Alzheimer disease $(A D)$ brains $(B, D)$ in gray matter (GM) (A, B) and in periventricular white matter (PVWM, C, D). LPS colocalized with 4',6-diamidino-2-phenylindole (DAPI)stained nuclei in control GM (E) and WM (G) including ependymal cells (G, arrowheads). The patterns of control LPS staining in

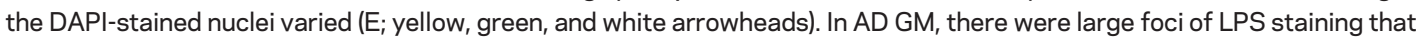
appeared to be plaques in cortex (Ctx) (B, F; white arrow), and other LPS-stained structures that appeared to be the size of nuclei in GM (B, F; yellow arrowheads). LPS staining was detected in control (C, G) and $A D(D, H)$ WM. DAPI staining of nuclei was decreased in $A D$ Ctx $(F)$ and in WM $(H)$ including ventricular ependymal cells $(H$, white arrowheads), likely indicating cell loss. LPS was detected in all $11 \mathrm{AD}$ brains and all 7 control brains by immunofluorescence. Bar $=25 \mu \mathrm{m}$.

Though the monoclonal antibodies were raised to $E$ coli molecules, they may not be specific for $E$ coli. PCR showed appropriate size bands for $E$ coli DNA in the majority of $\mathrm{AD}$ and control brains. Sequencing the bands showed that though most $100 \%$ identical hits were for $E$ coli, there were $100 \%$ identical hits for 

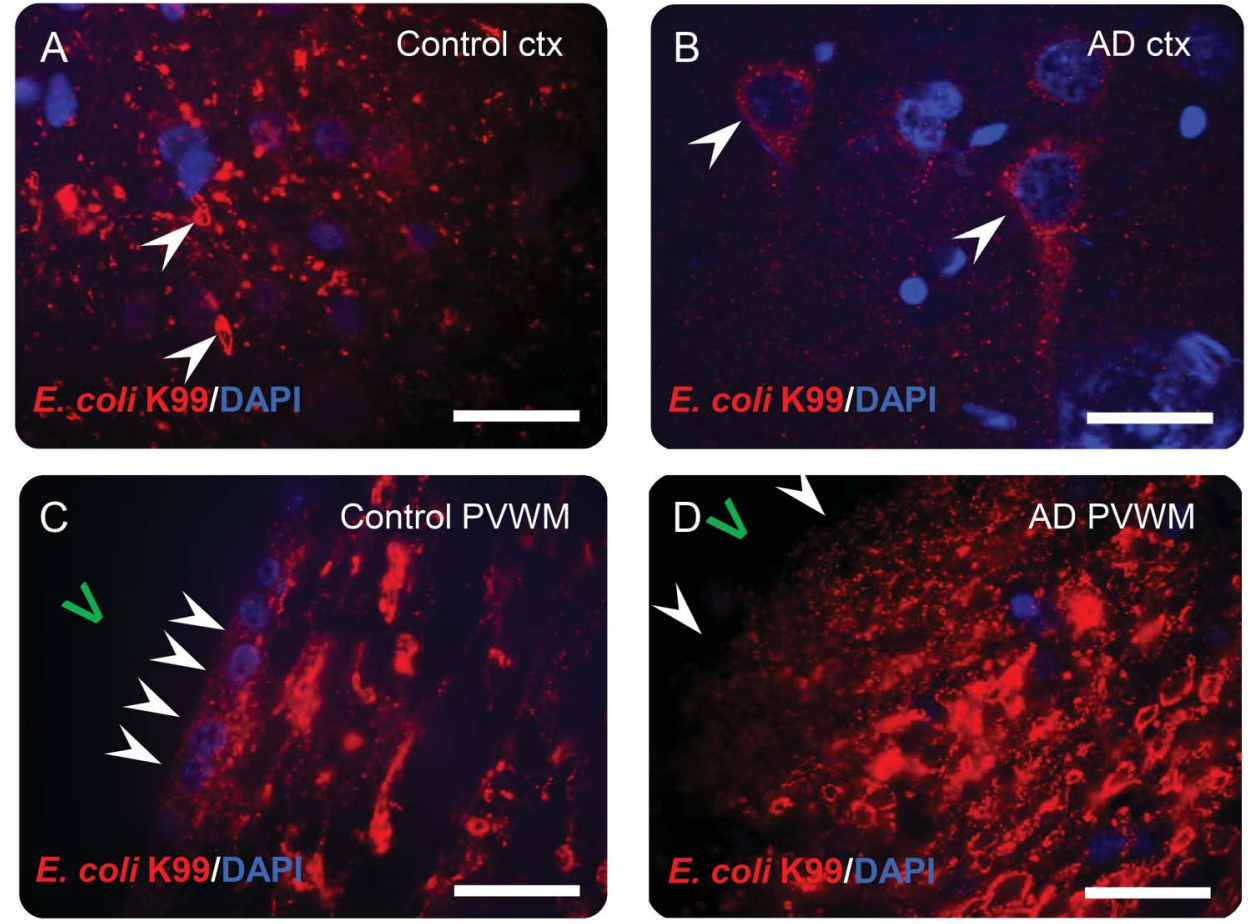

E coli K99 staining in control cortex (Ctx) was punctate and not associated with 4',6-diamidino-2-phenylindole (DAPI)stained nuclei (A). In control white matter, K99 staining appeared to be associated with fiber tracts (C). In Alzheimer disease (AD) gray matter (GM), E coli K99 pili protein was often found in pyramidal cells in the cytoplasm and not the nucleus (B, arrowheads). There was intense $E$ coli $\mathrm{K} 99$ pili protein staining in $A D$ periventricular white matter (PVWM) (D) with loss of normal DAPI-stained ependymal cells in AD brains ( $D$, arrowheads) compared to controls ( $C$, arrowheads). E coli K99 pili protein was detected in all $11 \mathrm{AD}$ brains and all 7 control brains by immunofluorescence. Bar $=25 \mu \mathrm{m}$.

a related Gram-negative family member, Shigella, which is due to the sequence homology between the 2 species. Thus, the data support the presence of proteins and DNA from $E$ coli or Gram-negative bacteria related to $E$ coli.

Our findings complement a recent RNAseq study that showed bacterially encoded 16s RNA sequences in all human brains with Gram-negative $\alpha$-Proteobacteria representing over $70 \%$ of bacterial sequences. ${ }^{16}$ The other $30 \%$ of bacterial classes varied widely, with $\gamma$-Proteobacteria, including $E$ coli, being present at $<5 \%$ of total bacterial transcripts found. ${ }^{16}$ Thus our data support this previous study.

A major question arises as to how Gram-negative bacterial LPS, proteins and DNA in this study, and $\alpha$-Proteobacteria molecules ${ }^{16}$ or Gram-positive bacterial peptidoglycan ${ }^{22,23}$ in other studies enter brain. In our LPS/ischemia/hypoxia animal model, we showed that LPS increased in rat brain over a period of 3 months after a single intraperitoneal injection that was associated with a parallel increase in IL-1 $\beta$ and granzyme $\mathrm{B}$ in brain. ${ }^{15}$ We postulated that IL-1 $\beta$-producing monocytes and granzyme B-producing cytotoxic $T$ cells or natural killer cells phagocytized the LPS in the periphery via Toll 4 receptors and carried LPS into brain. ${ }^{15}$ Gamma
Proteobacteria enterobacteriaceae like $E$ coli, and related family members like Salmonella and Shigella, cause diarrheal illness in humans, ${ }^{24}$ and some strains of $E$ coli are resident in the gastrointestinal tract. The virulence of enterotoxigenic $E$ coli that cause diarrhea are dependent on production of adhesins and enterotoxins, and the $E$ coli K99 pili protein found in control and AD brains is one of the surface antigens in enterotoxigenic (diarrhea) $E$ coli adhesive pili. ${ }^{25}$ It is tempting to speculate that this study provides another example of a gut-to-brain connection ${ }^{26}$ with gut being one possible source of brain $E$ coli supporting the concept of $\mathrm{AD}$ being a systemic disease. ${ }^{27} E$ coli from urinary tract and other infections could also be a source for brain bacterial molecules. Finally, since LPS derived from Gramnegative bacteria injures the blood-brain barrier, ${ }^{28}$ this could promote entry of LPS and other bacterial molecules into the brain.

Previous studies show that sporadic late-onset AD can be associated with infection. ${ }^{9-12}$ Infectious agents previously associated with AD include Spirochetes, $P$ gingivalis, Borrelia burgdorferi, Chlamydophila pneumonia, Helicobacter pylori, C glabrata, various fungi, herpesviruses, and cytomegalovirus. ${ }^{9-12} \mathrm{~A}$ major difference between previous studies and this 
Figure 4 Association of lipopolysaccharide (LPS) and Escherichia coli K99 pili protein with amyloid plaques in Alzheimer disease (AD) brains
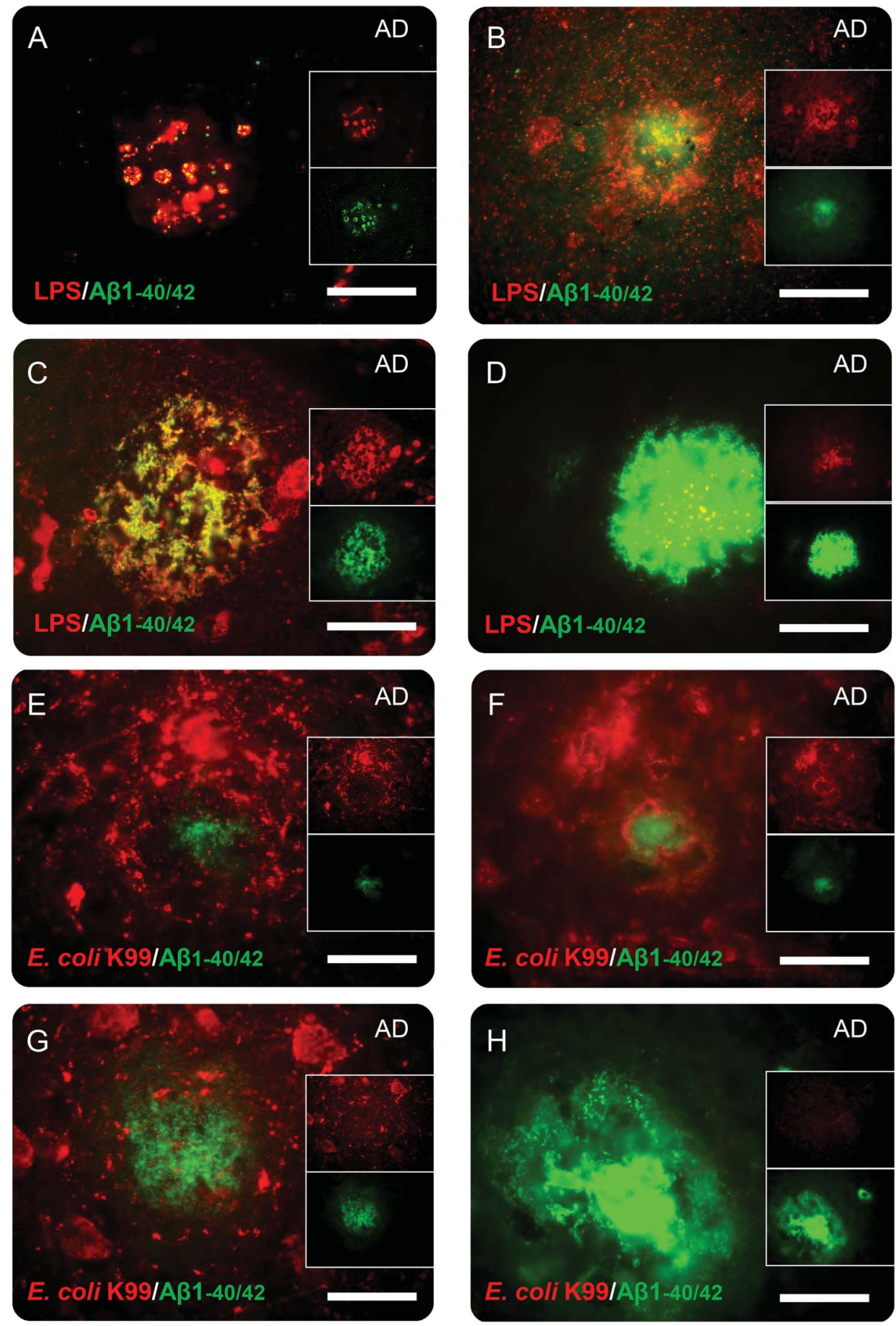

There were several different patterns of colocalization of LPS and $A \beta_{1-40 / 42}$ in AD brains. There were clusters of predominantly LPS particles that colocalized with $A \beta_{1-40 / 42}(A)$. There were $A \beta_{1-40 / 42}$ deposits that colocalized with LPS

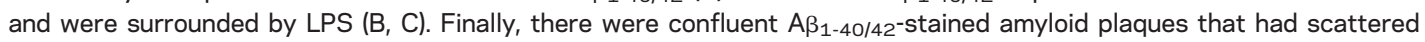
LPS particles within them (D). These LPS results contrasted with E coli K99 pili protein, which often surrounded small

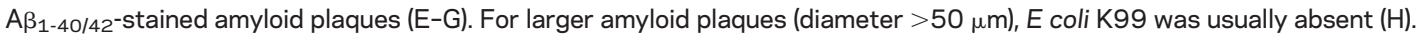
Bar $=25 \mu \mathrm{m}$.

one is that LPS colocalized with amyloid plaque and with perivascular amyloid in every AD brain.

LPS is the major component of the outer membrane of Gram-negative bacteria. Gram-negative bacteria include $\alpha$-Proteobacteria found in human brain ${ }^{16}$ and include $\gamma$-Proteobacteria like $E$ coli, molecules of which were found in brain in this study. LPS was colocalized with $A \beta_{1-40 / 42}$ in amyloid plaques 

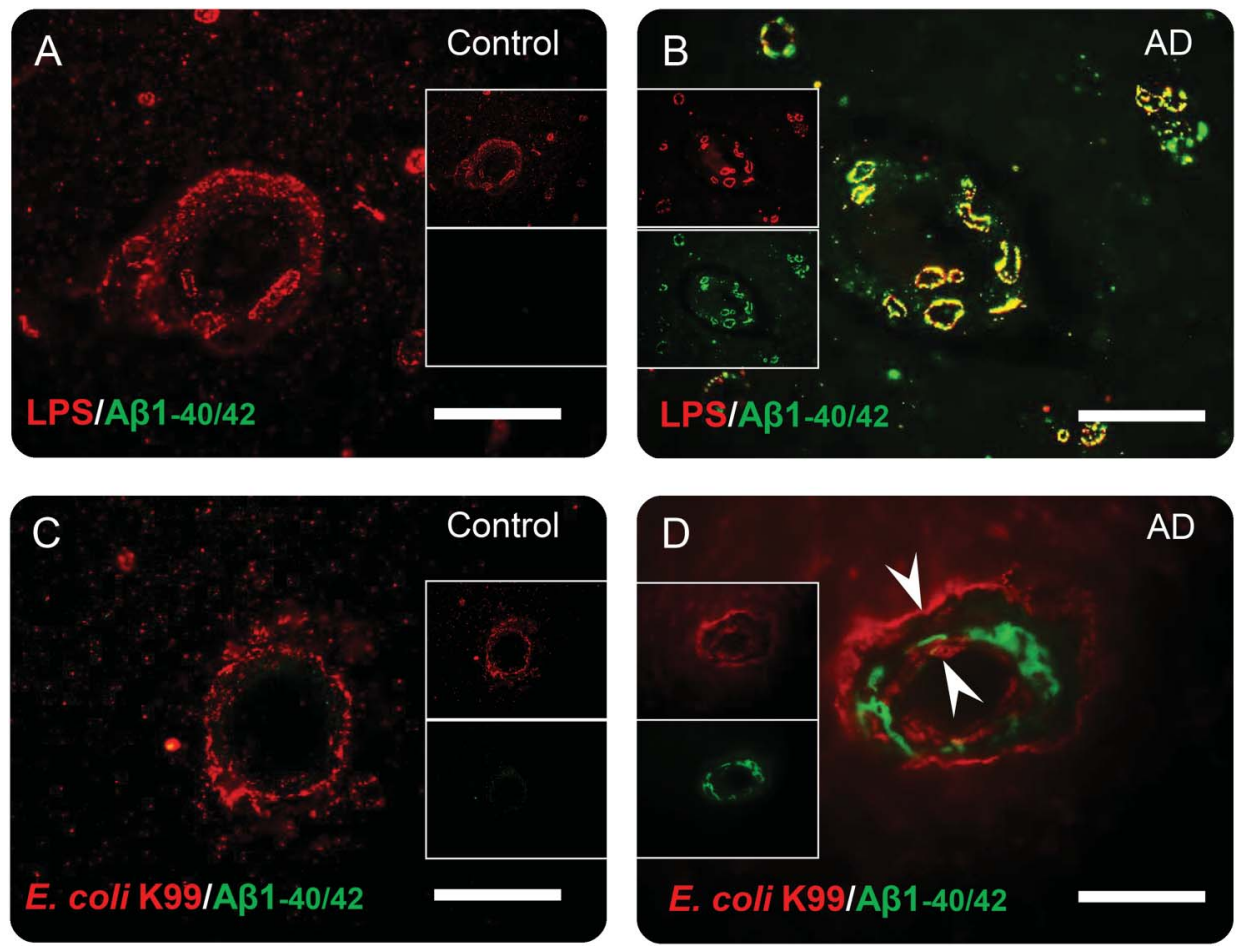

LPS and E coli K99 were also found in vessels of human brains. In control brains, both LPS (A) and E coli K99 pili protein (C) were localized in blood vessels that did not stain for $A \beta_{1-40 / 42}(A, C)$. LPS, E coli K99 pili protein, and $A \beta_{1-40 / 42}$ were localized in vessels of Alzheimer disease (AD) brains (B, D). $A \beta_{1-40 / 42}$ colocalized (yellow staining) with LPS in vessels in $A D$ brains (B). $A \beta_{1-40 / 42}$ was frequently sandwiched by but did not colocalize with $E$ coli $K 99$ pili protein (D, arrowheads). Bar $=25 \mu \mathrm{m}$.

and with perivascular $A \beta_{1-40 / 42}$ in all $\mathrm{AD}$ brains. In our recent animal study, systemic LPS combined with cerebral ischemia/hypoxia produced aggregates of myelin that colocalized with $A \beta_{1-40 / 42}$ in adult rat brains and the aggregates had features of amyloid plaques. ${ }^{15}$ These animal data, combined with the current human brain data, suggest the possibility that LPS in combination with other factors could cause $\mathrm{AD}$ neuropathology.

LPS and $E$ coli K99 pili protein in vessels and ependymal cells could contribute to vessel injury ${ }^{29}$ and ependymal injury ${ }^{17}$ and WM injury observed in $\mathrm{AD}$ brains. There was more K99 pili protein in GM and WM of AD brains, and both WM and GM are consistently damaged in $\mathrm{AD} \cdot{ }^{17,30}$ However, the current human data cannot determine if the bacterial molecules are a cause or consequence of the injury to $\mathrm{AD}$ brain.

There are limitations to this study. E coli could contaminate tissue samples. We used sterile techniques, sterile solutions, and sampled the core of frozen tissue blocks to reduce contamination. Evidence against $E$ coli contamination includes the finding that LPS and $E$ coli K99 staining patterns in control and $\mathrm{AD}$ brains were different, the staining patterns were consistent in all brains, and levels of K99 and LPS were higher in $\mathrm{AD}$ compared to control brains.
Studies of brain biopsies obtained during life would help address the possibility of contamination during autopsy, however.

The current study did not test whether there are live bacteria in human brain. However, a recent study found evidence for live bacteria in brain and supports the idea that every organ, including brain, has its own microbiome. ${ }^{16}$ Since this study focused on $E$ coli proteins and DNA, future studies will be needed to address the potential for other bacteria in $\mathrm{AD}$ pathogenesis.

\section{AUTHOR CONTRIBUTIONS}

Xinhua Zhan designed the studies, collected data, and wrote the manuscript. Boryana Stamova designed the studies, performed statistical analysis, and made changes to the manuscript. Lee-Way Jin provided brain samples, reviewed samples for correct diagnosis, and made changes to the manuscript. Charles DeCarli provided brain samples, reviewed samples for correct diagnosis, and made changes to the manuscript. Brett Phinney analyzed data and made changes to the manuscript. Frank R. Sharp designed the studies, wrote the manuscript, and made changes to the manuscript.

\section{ACKNOWLEDGMENT}

The authors thank the Alzheimer's Disease Center of University of California for providing brain samples.

\section{STUDY FUNDING}

This study was supported by NIH/NINDS grant RO1 AG042292 (F.R.S., C.D.), ADC grant AG P30 10129 (C.D.), and grants from The Rotary 
Coins for Alzheimer's Research Trust (CART) (F.R.S, X.Z.) and an Alzheimer's Disease Research Award from California Department of Public Health (F.R.S., X.Z.).

\section{DISCLOSURE}

The authors report no disclosures relevant to the manuscript. Go to Neurology.org for full disclosures.

Received March 8, 2016. Accepted in final form August 24, 2016.

\section{REFERENCES}

1. Holmes C, Butchart J. Systemic inflammation and Alzheimer's disease. Biochem Soc Trans 2011;39:898-901.

2. Dunn N, Mullee M, Perry VH, Holmes C. Association between dementia and infectious disease: evidence from a case-control study. Alzheimer Dis Assoc Disord 2005; 19:91-94.

3. Tyas SL, Manfreda J, Strain LA, Montgomery PR. Risk factors for Alzheimer's disease: a population-based, longitudinal study in Manitoba, Canada. Int J Epidemiol 2001, 30:590-597.

4. Verreault R, Laurin D, Lindsay J, De Serres G. Past exposure to vaccines and subsequent risk of Alzheimer's disease. CMAJ 2001;165:1495-1498.

5. Engelhart MJ, Geerlings MI, Meijer J, et al. Inflammatory proteins in plasma and the risk of dementia: the Rotterdam Study. Arch Neurol 2004;61:668-672.

6. Schmidt R, Schmidt H, Curb JD, Masaki K, White LR, Launer LJ. Early inflammation and dementia: a 25-year follow-up of the Honolulu-Asia aging study. Ann Neurol 2002;52:168-174.

7. Imbimbo BP. An update on the efficacy of non-steroidal anti-inflammatory drugs in Alzheimer's disease. Expert Opin Investig Drugs 2009;18:1147-1168.

8. Vlad SC, Miller DR, Kowall NW, Felson DT. Protective effects of NSAIDs on the development of Alzheimer disease. Neurology 2008;70:1672-1677.

9. Bibi F, Yasir M, Sohrab SS, et al. Link between chronic bacterial inflammation and Alzheimer disease. CNS Neurol Disord Drug Targets 2014;13:1140-1147.

10. Singhrao SK, Harding A, Poole S, Kesavalu L, Crean S. Porphyromonas gingivalis periodontal infection and its putative links with Alzheimer's disease. Mediators Inflamm 2015;2015:137357.

11. Noble JM, Scarmeas N, Celenti RS, et al. Serum IgG antibody levels to periodontal microbiota are associated with incident Alzheimer disease. PLoS One 2014;9:e114959.

12. Civitelli L, Marcocci ME, Celestino I, et al. Herpes simplex virus type 1 infection in neurons leads to production and nuclear localization of APP intracellular domain (AICD): implications for Alzheimer's disease pathogenesis. J Neurovirol 2015;21:480-490.

13. Chapman MR, Robinson LS, Pinkner JS, et al. Role of Escherichia coli curli operons in directing amyloid fiber formation. Science 2002;295:851-855.

14. Fowler DM, Koulov AV, Balch WE, Kelly JW. Functional amyloid: from bacteria to humans. Trends Biochem Sci 2007;32:217-224.
15. Zhan X, Cox C, Ander BP, et al. Inflammation combined with ischemia produces myelin injury and plaque-like aggregates of myelin, amyloid-beta and AbetaPP in adult rat brain. J Alzheimers Dis 2015;46:507-523.

16. Branton WG, Ellestad KK, Maingat F, et al. Brain microbial populations in HIV/AIDS: alpha-proteobacteria predominate independent of host immune status. PLoS One 2013;8:e54673.

17. Zhan X, Jickling GC, Ander BP, et al. Myelin injury and degraded myelin vesicles in Alzheimer's disease. Curr Alzheimer Res 2014;11:232-238.

18. Zhan X, Jickling GC, Ander BP, et al. Myelin basic protein associates with AbetaPP, Abeta1-42, and amyloid plaques in cortex of Alzheimer's disease brain. J Alzheimers Dis 2015;44:1213-1229.

19. Quinones B, Swimley MS, Narm KE, Patel RN, Cooley MB, Mandrell RE. O-antigen and virulence profiling of shiga toxin-producing Escherichia coli by a rapid and costeffective DNA microarray colorimetric method. Front Cell Infect Microbiol 2012;2:61.

20. Braak H, Braak E. Frequency of stages of Alzheimer-related lesions in different age categories. Neurobiol Aging 1997; 18:351-357.

21. Klemm P, Schembri MA. Bacterial adhesins: function and structure. International journal of medical microbiology. Int J Med Microbiol 2000;290:27-35.

22. Schrijver IA, van Meurs M, Melief MJ, et al. Bacterial peptidoglycan and immune reactivity in the central nervous system in multiple sclerosis. Brain 2001;124: 1544-1554.

23. Visser L, Melief MJ, van Riel D, et al. Phagocytes containing a disease-promoting Toll-like receptor/Nod ligand are present in the brain during demyelinating disease in primates. Am J Pathol 2006;169:1671-1685.

24. Fischer Walker CL, Sack D, Black RE. Etiology of diarrhea in older children, adolescents and adults: a systematic review. PLoS Negl Trop Dis 2010;4:e768.

25. Nagy B, Fekete PZ. Enterotoxigenic Escherichia coli (ETEC) in farm animals. Vet Res 1999;30:259-284.

26. Schmidt C. Mental health: thinking from the gut. Nature 2015;518:S12-S15.

27. Khan TK, Alkon DL. Peripheral biomarkers of Alzheimer's disease. J Alzheimers Dis 2015;44:729-744.

28. Erickson MA, Hartvigson PE, Morofuji Y, Owen JB, Butterfield DA, Banks WA. Lipopolysaccharide impairs amyloid beta efflux from brain: altered vascular sequestration, cerebrospinal fluid reabsorption, peripheral clearance and transporter function at the blood-brain barrier. J Neuroinflammation 2012;9:150.

29. Janota C, Lemere CA, Brito MA. Dissecting the contribution of vascular Alterations and aging to Alzheimer's disease. Mol Neurobiol 2015;53:37933811.

30. Bartzokis G, Sultzer D, Lu PH, Nuechterlein KH, Mintz J, Cummings JL. Heterogeneous age-related breakdown of white matter structural integrity: implications for cortical "disconnection" in aging and Alzheimer's disease. Neurobiol Aging 2004;25:843-851. 


\section{Neurology}

\section{Gram-negative bacterial molecules associate with Alzheimer disease pathology \\ Xinhua Zhan, Boryana Stamova, Lee-Way Jin, et al. \\ Neurology 2016;87;2324-2332 Published Online before print October 26, 2016 \\ DOI 10.1212/WNL.0000000000003391}

This information is current as of October 26, 2016

\begin{tabular}{|c|c|}
\hline $\begin{array}{l}\text { Updated Information \& } \\
\text { Services }\end{array}$ & $\begin{array}{l}\text { including high resolution figures, can be found at: } \\
\text { http://n.neurology.org/content/87/22/2324. full }\end{array}$ \\
\hline Supplementary Material & $\begin{array}{l}\text { Supplementary material can be found at: } \\
\text { http://n.neurology.org/content/suppl/2016/10/26/WNL.0000000000003 } \\
\text { 391.DC1 }\end{array}$ \\
\hline References & $\begin{array}{l}\text { This article cites } 30 \text { articles, } 4 \text { of which you can access for free at: } \\
\text { http://n.neurology.org/content/87/22/2324. full\#ref-list- } 1\end{array}$ \\
\hline Citations & $\begin{array}{l}\text { This article has been cited by } 2 \text { HighWire-hosted articles: } \\
\text { http://n.neurology.org/content/87/22/2324. full\#\#otherarticles }\end{array}$ \\
\hline Subspecialty Collections & $\begin{array}{l}\text { This article, along with others on similar topics, appears in the } \\
\text { following collection(s): } \\
\text { Alzheimer's disease } \\
\text { http://n.neurology.org/cgi/collection/alzheimers_disease }\end{array}$ \\
\hline Permissions \& Licensing & $\begin{array}{l}\text { Information about reproducing this article in parts (figures,tables) or in } \\
\text { its entirety can be found online at: } \\
\text { http://www.neurology.org/about/about_the_journal\#permissions }\end{array}$ \\
\hline Reprints & $\begin{array}{l}\text { Information about ordering reprints can be found online: } \\
\text { http://n.neurology.org/subscribers/advertise }\end{array}$ \\
\hline
\end{tabular}

Neurology ${ }^{\circledR}$ is the official journal of the American Academy of Neurology. Published continuously since 1951, it is now a weekly with 48 issues per year. Copyright @ 2016 American Academy of Neurology. All rights reserved. Print ISSN: 0028-3878. Online ISSN: 1526-632X.

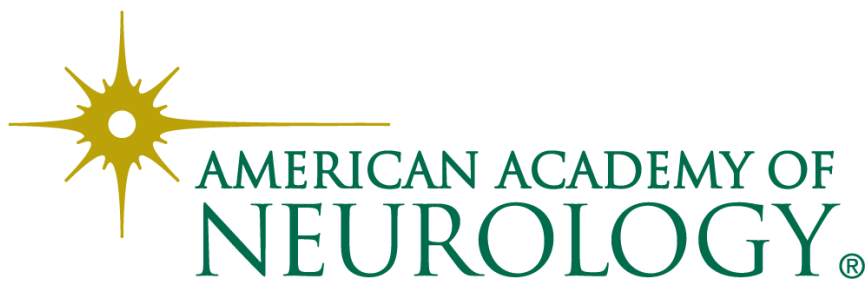

